\title{
Family Members of Patients with Abdominal Aortic Aneurysms are at Increased Risk for Aneurysms: Analysis of 618 Probands and their Families from the Liège AAA Family Study
}

\author{
Natzi Sakalihasan ${ }^{1}$, Jean-Olivier Defraigne ${ }^{1}$, Marie-Ange Kerstenne ${ }^{1}$, Jean-Paul Cheramy- \\ Bien ${ }^{1}$, Diane T. Smelser ${ }^{2}$, Gerard Tromp ${ }^{2}$, and Helena Kuivaniemi ${ }^{2,3}$ \\ Liège, Belgium and Danville, Pennsylvania, USA
}

\begin{abstract}
Background-The objectives were to answer the following questions using a well-characterized population in Liège, Belgium: 1) what percentage of abdominal aortic aneurysm (AAA) patients have a positive family history for AAA, 2) what is the prevalence of AAAs among relatives of AAA patients; and 3) do familial and sporadic AAA cases differ in clinical characteristics.

Methods and Results-Unrelated AAA patients diagnosed at the Cardiovascular Surgery Department, University Hospital of Liège, Belgium, between 1999 and 2012 were invited to the study. A detailed family history was obtained in interviews and recorded using Progeny software. In the initial interview $62(10 \%)$ of the 618 AAA patients reported a positive family history for AAA. We divided the 618 patients into two study groups: Group I: 296 AAA patients (268; $91 \%$ males) were followed up with computerized tomography combined with positron emission tomography, and Group II: 322 AAA patients (295; 92\% males) whose families were invited to ultrasonography screening. Ultrasonography screening identified 24 new AAAs among 186 relatives ( $\geq 50$ years) of 144 families yielding a prevalence of $13 \%$. The highest prevalence (25\%) was found among brothers. By combining the number of AAAs found by ultrasonography screening with those diagnosed previously the observed lifetime prevalence of AAA was estimated to be $32 \%$ in brothers. The familial AAA cases were more likely to have a ruptured AAA than the sporadic cases ( $8 \%$ vs. $2.4 \% ; P<0.0001)$.
\end{abstract}

Conclusions-The findings confirm previously found high prevalence of AAA among brothers, support genetic contribution to AAA pathogenesis and provide rationale for targeted screening of relatives of AAA patients.

\footnotetext{
(C) 2013 Annals of Vascular Surgery Inc. Published by Elsevier Inc. All rights reserved.

Correspondence to: Helena Kuivaniemi, MD, PhD, FAHA, The Sigfried and Janet Weis Center for Research, Geisinger Health System, 100 North Academy Avenue, MC 26-10, Danville, PA 17822-2610, USA; Tel: (570) 271-5593; Fax: (570) 271-6701; shkuivaniemi@geisinger.edu, or Natzi Sakalihasan, MD,PhD, nsaka@chu.ulg.ac.be.

1 Cardiovascular Surgery Department, University Hospital of Liège, CHU, Liège, Belgium.

${ }^{2}$ The Sigfried and Janet Weis Center for Research, Geisinger Health System, Danville, Pennsylvania, USA.

${ }^{3}$ Department of Surgery, Temple University School of Medicine, Philadelphia, Pennsylvania, USA.

Publisher's Disclaimer: This is a PDF file of an unedited manuscript that has been accepted for publication. As a service to our customers we are providing this early version of the manuscript. The manuscript will undergo copyediting, typesetting, and review of the resulting proof before it is published in its final citable form. Please note that during the production process errors may be discovered which could affect the content, and all legal disclaimers that apply to the journal pertain.
} 


\section{Keywords}

abdominal aortic aneurysm; ultrasonography screening; family study; risk factors; family history

\section{INTRODUCTION}

Abdominal aortic aneurysms (AAAs) are a common complex disease with both environmental and genetic risk factors. ${ }^{1-5}$ The aggregation of AAA in families was first reported in the 1970s and 1980s. ${ }^{6-9}$ The largest collection of 233 AAA families was published in 2003. ${ }^{10}$

Familial clustering of AAA has also been documented in twin studies. ${ }^{11}$ The Swedish Twin Study based on data available on all twins born in Sweden since 1886 with 172,890 twins registered identified 265 twins with an AAA. ${ }^{11}$ Monozygotic (identical) twins had a $24 \%$ probability of having an aneurysm if the other twin had an AAA, whereas the probability was only $4.8 \%$ in dizygotic twins. Phenotypic variance determined by genetic factors was estimated to be $70 \%$ and non-shared environmental effects $30 \%{ }^{11}$

The objective of the current study was to analyse the results of the Liège AAA Family Study consisting of 618 unrelated AAA patients diagnosed at the University Hospital of Liège to answer the following questions: 1) what percentage of AAA patients (referred here as "AAA probands") have a positive family history for AAA, 2) what is the prevalence of AAA among the relatives of AAA probands, and 3) do familial AAA (FAAA) cases differ from non-familial (sporadic) AAA cases in clinical characteristics.

\section{METHODS}

\section{Patient and Data Collection for the Liège AAA Family Study}

The Liège AAA Family Study includes a total of 618 unrelated AAA patients (563 men, 91\%), diagnosed at the Cardiovascular Surgery Department, University Hospital of Liège, CHU, Liège, Belgium, between 1999 and 2012 (Table I, Figure 1). The term proband will be used for each of these 618 AAA patients, since each of them was the first affected person in their families who came to our attention. All of the probands were of European ancestry. Pedigrees of the 618 AAA probands were constructed using Progeny (Progeny software LLC, South Bend, IN, USA). We used the Johnston et al. ${ }^{12}$ definition of AAA-a diameter of infrarenal aorta $\geq 3 \mathrm{~cm}$-which has been used by other investigators. ${ }^{13}, 14$ Individuals with heritable connective tissue disorders, such as Marfan syndrome or the vascular type of Ehlers-Danlos syndrome, were excluded. The study was approved by the Ethics Committee of the University Hospital of Liège, CHU, Liège, Belgium.

We divided the 618 probands into two study groups (Figure 1). Group I: 296 AAA probands (268; $91 \%$ males) were diagnosed at the Cardiovascular Surgery Department, University Hospital of Liège, CHU, Liège, Belgium, between 2008 and 2012 and were followed up with computerized tomography combined with positron emission tomography (PET-CT). Group II: 322 AAA probands (295; 92\% males), operated on at the Cardiovascular Surgery Department, University Hospital of Liège, between 1999 and 2003, either as elective repair 
$(n=317)$ or emergency operations for ruptured AAA $(n=5)$, and whose families were invited to ultrasonography (US) screening. In the current report, we describe the findings of the family studies based on these two groups, whereas the PET results on AAA progression will be reported elsewhere. Our group uses PET extensively to study AAA pathogenesis and rupture risk. ${ }^{15-17}$

\section{Ultrasonography Screening of Relatives}

Consent for contacting the family members of Group II AAA probands was obtained, and the available relatives were invited to the US screening study. Both the AAA probands and their spouses were interviewed, whenever possible, to gather information for constructing the pedigrees. Personnel specifically trained for this study contacted the first-degree relatives of the AAA patients, as well as the spouses, and invited them to participate in the study. A small number $(n=9)$ of other relatives was also screened. Written informed consent was obtained from the participants who agreed to US examination of the abdominal aorta. If an US examination or an equivalent examination such as CT scan had been completed within the last 6 months, a copy of the report was requested and no additional US examination was done.

Participants to the US screening were also asked to complete a questionnaire about their general health information (smoking history, past medical history on hypertension, hypercholesterolemia, heart disease, peripheral vascular disease and diabetes) as well as sex, race and age.

\section{Ultrasonography Screening of Spouses}

Spouses of the AAA probands were also invited to US screening. The spouse group could serve as a control group, since most of the time spouses are exposed to similar environmental exposures, eat the same food and live in the same house.

\section{Statistical Methods}

Statistical analysis was carried out by using Fisher's exact test as implemented in Statistical Analysis Software (SAS V.9.3 for Windows, SAS Institute Inc., Cary, NC). Odds ratios (ORs) and 95\% confidence intervals (CIs) were calculated for prevalence of AAA among family members and risk factors such as smoking, hypertension, and hypercholesterolemia.

Observed lifetime prevalence of AAA was calculated by combining the number of already known AAA cases with the number of asymptomatic AAA cases identified in this study using US screening.

\section{RESULTS}

\section{The Liège AAA Family Study}

Investigators at the University Hospital of Liège, Belgium, have recruited a total of 618 AAA probands into the Liège AAA Family Studybetween 1999 and 2012 (Table I). Majority $(563 ; 91 \%)$ of these patients were male. The cardiovascular risk factor profile for these patients is summarized in Table I. Majority $(520 ; 84 \%)$ of the patients were either 
current or past smokers. In the initial interview, altogether $62(10 \%)$ of the probands reported a positive family history for AAA and were designated as FAAA probands. US screening identified relatives with AAA in 17 additional families bringing the total number of FAAA probands to 79 (13\%) (see below for details).

We present the 618 probands here as two study groups based on the time period of recruitment and the type of follow-up studies carried out: 1) Group I: 296 AAA probands (268; 91\% males; Table II) who were followed up with PET-CT, and 2) Group II: 322 AAA probands (295; 92\% males; Table III) whose families were invited to US screening. Extensive family history questionnaire was administered to both groups.

Characteristics of the 296 AAA probands in Group I are summarized in Table II. The mean

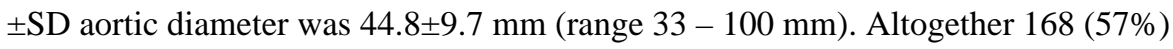
probands underwent elective AAA repair surgery, seven (2.4\%) were operated on for ruptured AAA, and the remaining $121(41 \%)$ patients had AAAs <55 mm and were, therefore, under surveillance. In Group I, 42 (14\%) probands reported a positive family history for AAA. Based on the interview, there were 55 relatives with AAA (14 brothers, 15 fathers, seven mothers, five sisters, two grandfathers, one son, one daughter and ten other relatives). Most (32) FAAA probands had only one known affected relative, seven had two affected relatives and three had three affected relatives.

Comparison of the clinical characteristics of FAAA and sporadic probands in Group I (Table II) revealed no significant differences except FAAA cases were less likely to have heart disease $(P=0.036)$ and they were on average two years younger than their sporadic counterparts $(P=0.030)$.

\section{Ultrasonography Screening Study}

To estimate the prevalence of AAA among relatives of AAA patients, Group II AAA probands were contacted to invite their relatives for US screening. During the initial interview of the 322 Group II probands we found out that $20(6.2 \%)$ probands had a positive family history for AAA with a total of 29 known AAA cases. In addition, we were able to collect information on 774 living relatives with no known AAA who were then invited to the US screening (Figure 1). Of these, 303 (39\%) could not be reached, 264 (34\%) lived outside Liège or were too young (< 50 years) and 21 (2.7\%) refused participation. Altogether, 186 relatives, who were $\geq 50$ years, from 144 independent families participated in the US screening program (Figure 1 and Table III). In addition, 78 relatives < 50 years of age were screened since they were so concerned about their risk of AAA that they attended the screening events together with their older relatives (Table III). We report the results for these two age groups separately, since increasing age is a known significant risk factor for AAA (Table III).

We also offered US screening to spouses. A total of 226 AAA probands had a spouse, 45 of whom (two spouses were deceased and 179 did not participate for other reasons) participated in the study and had an abdominal US examination. None of them had an AAA. Unfortunately the participation rates were too low and the number of screened spouses was only 45 making it impossible to provide any meaningful statistics. The spouses did, 
however, contribute to the study by helping with the collection of the family history information.

When family information was gathered, we found out that 10 relatives (eight brothers, one son and one other relative) of the AAA probands in the 144 families that participated in the US screening, were already known to have an AAA (Table III, Figure 1). These diagnoses were confirmed using medical records, but no other risk factor information was readily available on these 10 individuals.

From the participants, 150 siblings (69 brothers and 81 sisters) representing 44\% (150/341) of all known living siblings, 30 children $(13 \%, 30 / 233)$, two mothers and four other relatives of 144 AAA probands were at least 50 years old and had an abdominal US examination as part of this screening program (Figure 1 and Table III). Table III summarizes the results of the US screening for AAA in these groups. Seventeen of the 69 brothers (25\%), three (3.7\%) of the 81 sisters, one of $15(6.7 \%)$ sons, one of 15 (6.7\%) daughters, and two of four other relatives of the AAA probands screened were found to have an AAA. The overall prevalence of AAA among all the screened relatives who were $\geq 50$ years was $13 \%$ (24/186). The highest prevalence of $25 \%$ was found among brothers (Table III). Among the 78 relatives $<50$ years of age, only one person, a son, was found to have an AAA. It is also of interest to note that within six years of the initial US screening, 16 relatives who could not be reached when the initial US screening was conducted, developed an AAA. These 16 individuals were not included in the analyses.

By combining the number of AAAs found by US screening to those diagnosed previously in the 144 families, the observed lifetime prevalence of AAA was estimated. AAA was present in $32 \%$ of the brothers (25/77) and $3.7 \%$ of the sisters (3/81) of the AAA patients (Table III). The observed lifetime prevalence of AAA was 18\% (28/158) among the siblings of the 144 AAA probands, and $18 \%(35 / 196)$ among all the relatives who were $\geq 50$ years old.

When comparing the characteristics of the relatives (who were $\geq 50$ years old) with and without AAA in the US screening study, as expected, male relatives had a higher prevalence of AAA than female relatives ( $22 \%$ vs. $5 \%$; Table IV). The mean age of the 24 relatives with AAA was $70 \pm 9.5$ years, with the youngest person being 50 years and the oldest 87 years of age (Table V). Five (21\%) of them were younger than 65 years old (Table IV). Among both males and females, older relatives had a higher prevalence of AAA (Table IV).

Comparison of other known risk factors for AAA between the relatives (who were $\geq 50$ years old) with or without AAA showed that fewer of the relatives without AAA had heart disease (Table V). Also, only $42 \%$ of the relatives without AAA were current or past smokers, whereas the percentages were $85 \%$ and $54 \%$ in the AAA probands and their affected relatives, respectively (Table V). The risk of AAA among smokers was OR (95\% $\mathrm{CI})=3.2(1.7-5.9)$ in males, $\mathrm{OR}=7.5(2.1-10)$ in females, and $\mathrm{OR}=6.7(4.3-10)$ in the entire group of 346 AAA patients in Group II compared to the 162 relatives without AAA (Table VI). 


\section{Comparison of Clinical Features between FAAA and Sporadic AAA}

It is of interest to note that there were 15 ruptured AAAs among the 79 FAAA probands and their 109 affected relatives in Group I and II combined yielding a rupture rate of $8 \%$, whereas there were only 13 ruptured AAAs among the 539 sporadic AAA probands resulting in a rupture rate of $2.4 \%(P<0.0001)$. Another notable difference was in the number of probands with heart disease: FAAA probands were less likely to have heart disease than the sporadic AAA probands ( $28 \%$ vs. $40 \%$; $P=0.042$; Table I).

\section{Estimation of Familial Prevalence of AAA}

After combining the results of the family history interviews and the US screening program, a total of 79 (13\%) of the 618 Liège Family Study families had at least two affected individuals (Figure 1). Most (57; 72\%) of the families had two affected family members, 15 (19\%) had three affected individuals and seven (8.9\%) had four or more affected individuals. In Figure 2, two families are shown with three and six family members diagnosed with AAA. As can be seen, most of the individuals were diagnosed with AAA in their 60's to 80's.

\section{DISCUSSION}

Three different approaches have been used to estimate the prevalence of AAA among family members of AAA patients: 1) collect family information from the proband using interviews and family history questionnaires (Table VII); 2) screen the family members with aortic imaging for detection of asymptomatic AAAs (Table VIII); and 3) use national registries to identify related individuals from hospital discharge and cause of death data bases. ${ }^{18}$ In the current study we employed the first two approaches in the Liège AAA Family Study consisting of 618 unrelated AAA patients diagnosed at the University Hospital of Liège, Belgium.

Studies using interviews summarized in Table VII found that $12 \%$ (range $6-36 \%$ ) of AAA patients have relatives with AAA. Interviews allow inclusion of family members that may not be able to attend an US screening examination but the study relies on the patient or relative to provide accurate medical information of the family. It also requires that the relatives must already have a diagnosis of AAA leaving out asymptomatic, undiagnosed AAA cases.

One of the earliest interview studies, carried out by Johansen and Koepsell in 1986, found that $19 \%$ of the AAA patients interviewed had relatives who were also diagnosed with AAA. ${ }^{19}$ In contrast, only $2.4 \%$ of individuals without AAA knew of any relative with AAA in their families. Johnston and Scobie ${ }^{20}$ reported on 666 patients that underwent surgery for non-ruptured AAA and found positive family history for AAA in only $6.1 \%$ of these patients. A higher proportion (9.2\%) of 985 aneurysm patients (with at least a $4 \mathrm{~cm}$ aneurysm) studied by Lederle et al. ${ }^{21}$ reported a positive family history for AAA. In the current study $10 \%$ of the AAA probands reported a positive family history of AAA in the initial interview. 
Due to the potential limitations of interviews, the prevalence of AAA among family members could be estimated based on US screening allowing for the accurate determination of an AAA in asymptomatic family members. Summary on all studies that screened family members for AAA with an aortic US examination are presented in Table VIII. The overall prevalence of AAA in these studies was $12 \%$ (range 0 to $30 \%$ ) among all relatives. The large range of prevalence most likely reflects the study group analyzed. For example, if a group had a larger percentage of smokers, the incidence would be increased due to the additive risk factor of smoking. ${ }^{22}$ Because of the associated costs, all of these studies were relatively small with 300 or fewer participants. The current study is among the largest with 264 relatives, 186 of whom were $\geq 50$ years old, screened by US.

The risk of AAA depends greatly not only on smoking but also on sex as displayed also in the current study (Tables I-VI). A brother of an AAA patient has a $20 \%$ overall risk of developing an AAA as compared to an overall risk of $5.6 \%$ in a sister (Table VIII). Regardless of sex, the prevalence of AAA in relatives of AAA patients is increased as compared to the general population. Based on a necropsy study from Malmö, Sweden ${ }^{23}$, of 45,838 autopsies performed from 1958-1986, the overall prevalence of AAA was 3.2\%, $4.3 \%$ in males and $2.1 \%$ in females. A large US screening study on 73,451 veterans in the USA identified 3,366 aneurysms that were $>3 \mathrm{~cm}$ giving an overall prevalence of $4.6 \%$. $^{21}$ About $76 \%$ of the veterans were ever smokers, and therefore at high risk for aneurysm development. The ORs for smoking in the current study (Table VI) were comparable to the ORs in the US screening study of veterans. ${ }^{21}$ Another US screening study examined 8,234 Italians, age 65 years or greater and found a $6.2 \%$ prevalence of AAA. ${ }^{24}$ The high prevalence in this particular study was likely due to the advanced age of the participants. Consistent with these findings, in the current study the prevalence of AAA was also higher among relatives of $\succeq 65$ years as well as in smokers.

A study using the Swedish Twin Registry obtained estimates of genetic and environmental contributions to AAA development. ${ }^{11}$ Based on hospital discharge codes 265 twins with AAA were identified in the registry. The number of monozygotic twin pairs, in which both had AAA, was only seven, whereas the number of discordant (only one of the twins in the pair had AAA) monozygotic twin pairs was 44 . Thus the probability of the other twin to have AAA, if his/her twin pair had an AAA, was $24 \%$. In contrast, the prevalence of AAA among brothers of AAA patients has been reported to be between 20 and $43 \%$ in eight independent studies including the current study (Table VIII). Additional risk factors, such as smoking, as well as geographical differences, could increase the AAA risk among brothers from that predicted by genetics alone.

Two recent studies on clinical management of FAAA have provided important insights. ${ }^{25,} 26$ One of the studies found poorer outcomes with FAAA than sporadic AAA patients after endovascular aneurysm repair ${ }^{26}$, and the other study reported greater involvement of other aortic sections in familial forms of aortic aneurysms. ${ }^{25}$

Our study is one of the largest studies investigating the role of positive family history of AAA with 618 probands (Tables VII and VIII). The limitations of the current study are similar to previous studies and include 1) difficulty in obtaining a detailed and accurate 
family history from study participants; and 2) low participation rates by the relatives to the US screening. Despite these limitations the results seem consistent with previous literature (Tables VII and VIII) and between Groups I (interview only) and II (interview and US screening) in the current study. With additional funding future studies of similar nature could be improved by implementing use of portable US units to reach the relatives in more distant areas and making it easier for the participants to attend US screening. Such studies should also have a plan for follow-up measurements to be able to calculate growth rates. Incorporating blood draws into the work flow and storing the samples in a biobank for future genetic studies is also needed.

In conclusion, family history is an important risk factor for the development of AAAs and can be utilized to help identify patients at high risk for AAA development. The highest prevalence of AAA was found among brothers. Clinically the FAAA cases differed from sporadic cases in two study metrics: 1) they were more likely to have a ruptured AAA ( $8 \%$ vs. $2.4 \%$; $P<0.0001$ ), and 2) they were less likely to suffer from heart disease. With improved population screening in Liège, rupture rates have continued to decline, but the elevated rates in FAAA group are still noticeable. ${ }^{27}$ Identification of genetic risk factors for AAA is likely to provide means for more accurate targeted screening of patients at higher risk for AAA development. Until such genetic markers are available for clinical use, family history of AAA provides a useful proxy for finding individuals benefiting from US screening to detect AAA. Furthermore, operative management of individuals with FAAA could differ due to a higher rate of complications. The results presented in this study are likely to be generalizable to the populations of Western countries with similar risk factor profiles including smoking patterns. ${ }^{28}$

\section{Acknowledgments}

\section{Sources of Funding}

The study was funded in part by the National Heart, Lung, and Blood Institute, NIH (HL045996), the University of Liège, and the European Community Fighting Aneurysmal Disease (FAD) project (FP-7, HEALTH F2-2008-200647)

\section{References}

1. Sakalihasan N, Limet R, Defawe OD. Abdominal aortic aneurysm. Lancet. 2005; 365:1577-1589. [PubMed: 15866312]

2. Golledge J, Muller J, Daugherty A, Norman P. Abdominal aortic aneurysm: pathogenesis and implications for management. Arterioscler Thromb Vasc Biol. 2006; 26:2605-2613. [PubMed: 16973970]

3. Kuivaniemi, H.; Ryer, EJ.; Yoon, YR.; Elmore, JR. Genetic risk factors for abdominal aortic aneurysms. In: Fischhof, D.; Hatig, F., editors. Aortic Aneurysms: Risk Factors, Diagnosis, Surgery \& Repair. New York: Nova Science Publishers; 2013. p. 1-29.

4. Kuivaniemi, H.; Tromp, G.; Carey, DJ.; Elmore, JR. The Molecular Biology and Genetics of Aneurysms. In: Homeister, JW.; Willis, MS., editors. Molecular and Translational Vascular Medicine. New York: Springer Science+Business Media; 2012. p. 3-33.

5. Hinterseher I, Tromp G, Kuivaniemi H. Genes and abdominal aortic aneurysm. Ann Vasc Surg. 2011; 25:388-412. [PubMed: 21146954]

6. Clifton MA. Familial abdominal aortic aneurysms. Br J Surg. 1977; 64:765-766. [PubMed: 588966] 
7. Norrgard O, Rais O, Angquist KA. Familial occurrence of abdominal aortic aneurysms. Surgery. 1984; 95:650-656. [PubMed: 6729702]

8. Tilson MD, Seashore MR. Human genetics of the abdominal aortic aneurysm. Surg Gynecol Obstet. 1984; 158:129-132. [PubMed: 6695305]

9. Tilson MD, Seashore MR. Fifty families with abdominal aortic aneurysms in two or more first-order relatives. Am J Surg. 1984; 147:551-553. [PubMed: 6538765]

10. Kuivaniemi H, Shibamura H, Arthur C, et al. Familial abdominal aortic aneurysms: collection of 233 multiplex families. J Vasc Surg. 2003; 37:340-345. [PubMed: 12563204]

11. Wahlgren CM, Larsson E, Magnusson PK, Hultgren R, Swedenborg J. Genetic and environmental contributions to abdominal aortic aneurysm development in a twin population. J Vasc Surg. 2010; 51:3-7. [PubMed: 19939604]

12. Johnston KW, Rutherford RB, Tilson MD, Shah DM, Hollier L, Stanley JC. Suggested standards for reporting on arterial aneurysms. Subcommittee on Reporting Standards for Arterial Aneurysms, Ad Hoc Committee on Reporting Standards, Society for Vascular Surgery and North American Chapter, International Society for Cardiovascular Surgery. J Vasc Surg. 1991; 13:452458. [PubMed: 1999868]

13. Baird PA, Sadovnick AD, Yee IM, Cole CW, Cole L. Sibling risks of abdominal aortic aneurysm. Lancet. 1995; 346:601-604. [PubMed: 7651004]

14. Lederle FA, Johnson GR, Wilson SE. Abdominal aortic aneurysm in women. J Vasc Surg. 2001; 34:122-126. [PubMed: 11436084]

15. Courtois A, Nusgens BV, Hustinx R, et al. 18F-FDG uptake assessed by PET/CT in abdominal aortic aneurysms is associated with cellular and molecular alterations prefacing wall deterioration and rupture. J Nucl Med. 2013; 54:1740-1747. [PubMed: 24009278]

16. Xu XY, Borghi A, Nchimi A, et al. High levels of 18F-FDG uptake in aortic aneurysm wall are associated with high wall stress. Eur J Vasc Endovasc Surg. 2010; 39:295-301. [PubMed: 19926315]

17. Sakalihasan N, Van Damme H, Gomez P, et al. Positron emission tomography (PET) evaluation of abdominal aortic aneurysm (AAA). Eur J Vasc Endovasc Surg. 2002; 23:431-436. [PubMed: 12027471]

18. Larsson E, Granath F, Swedenborg J, Hultgren R. A population-based case-control study of the familial risk of abdominal aortic aneurysm. J Vasc Surg. 2009; 49:47-50. [PubMed: 19028058]

19. Johansen K, Koepsell T. Familial tendency for abdominal aortic aneurysms. JAMA. 1986; 256:1934-1936. [PubMed: 3761500]

20. Johnston KW, Scobie TK. Multicenter prospective study of nonruptured abdominal aortic aneurysms. I. Population and operative management. J Vasc Surg. 1988; 7:69-81. [PubMed: 3275808]

21. Lederle FA, Johnson GR, Wilson SE, et al. Prevalence and associations of abdominal aortic aneurysm detected through screening. Aneurysm Detection and Management (ADAM) Veterans Affairs Cooperative Study Group. Ann Intern Med. 1997; 126:441-449. [PubMed: 9072929]

22. Lederle FA. The rise and fall of abdominal aortic aneurysm. Circulation. 2011; 124:1097-1099. [PubMed: 21900095]

23. Bengtsson H, Bergqvist D, Sternby NH. Increasing prevalence of abdominal aortic aneurysms. A necropsy study. Eur J Surg. 1992; 158:19-23. [PubMed: 1348634]

24. Palombo D, Lucertini G, Pane B, Mazzei R, Spinella G, Brasesco PC. District-based abdominal aortic aneurysm screening in population aged 65 years and older. J Cardiovasc Surg (Torino). 2010; 51:777-782.

25. Brown CR, Greenberg RK, Wong S, et al. Family history of aortic disease predicts disease patterns and progression and is a significant influence on management strategies for patients and their relatives. J Vasc Surg. 2013; 58:573-581. [PubMed: 23809203]

26. van de Luijtgaarden KM, Bastos Goncalves F, Hoeks SE, et al. Familial abdominal aortic aneurysm is associated with more complications after endovascular aneurysm repair. J Vasc Surg. 2013 
27. Verloes A, Sakalihasan N, Koulischer L, Limet R. Aneurysms of the abdominal aorta: familial and genetic aspects in three hundred thirteen pedigrees. J Vasc Surg. 1995; 21:646-655. [PubMed: 7707569]

28. Strong, K.; Bonita, R. The SuRF Report 1. Surveillance of Risk Factors related to Noncommunicable Diseases: Current status of global data. Geneva, Switzerland: World Health Organization; 2003. Available from: http://apps.who.int/iris/bitstream/ 10665/42732/1/9241580305.pdf

29. Powell JT, Greenhalgh RM. Multifactorial inheritance of abdominal aortic aneurysm. Eur J Vasc Surg. 1987; 1:29-31. [PubMed: 3503759]

30. Cole CW, Barber GG, Bouchard AG, et al. Abdominal aortic aneurysm: consequences of a positive family history. Can J Surg. 1989; 32:117-120. [PubMed: 2920314]

31. Darling RC 3rd, Brewster DC, Darling RC, et al. Are familial abdominal aortic aneurysms different? J Vasc Surg. 1989; 10:39-43. [PubMed: 2787414]

32. Majumder PP, St Jean PL, Ferrell RE, Webster MW, Steed DL. On the inheritance of abdominal aortic aneurysm. Am J Hum Genet. 1991; 48:164-170. [PubMed: 1985458]

33. Lawrence PF, Wallis C, Dobrin PB, et al. Peripheral aneurysms and arteriomegaly: is there a familial pattern? J Vasc Surg. 1998; 28:599-605. [PubMed: 9786252]

34. Salkowski A, Greb A, Al-Aouar R, et al. Familial incidence of abdominal aortic aneurysms. J Genet Counsel. 1999; 8:407. (abstract).

35. Rossaak JI, Hill TM, Jones GT, Phillips LV, Harris EL, van Rij AM. Familial abdominal aortic aneurysms in the Otago region of New Zealand. Cardiovasc Surg. 2001; 9:241-248. [PubMed: 11336847]

36. Nischan, J.; Lenk, GM.; Boddy, AM.; Lillvis, JH.; Tromp, G.; Kuivaniemi, H. Abdominal aortic aneurysms- a complex genetic disease. In: Laurent, A.; Morel, E., editors. Aneurysms: Types, Risks, Formation and Treatment. Hauppage, NY: Nova Science Publishers, Inc; 2010. p. 35-93.

37. Bengtsson H, Norrgard O, Angquist KA, Ekberg O, Oberg L, Bergqvist D. Ultrasonographic screening of the abdominal aorta among siblings of patients with abdominal aortic aneurysms. Br J Surg. 1989; 76:589-591. [PubMed: 2667691]

38. Collin J, Walton J. Is abdominal aortic aneurysm familial? BMJ. 1989; 299:493. [PubMed: 2507033]

39. Webster MW, St Jean PL, Steed DL, Ferrell RE, Majumder PP. Abdominal aortic aneurysm: results of a family study. J Vasc Surg. 1991; 13:366-372. [PubMed: 1999855]

40. Adamson J, Powell JT, Greenhalgh RM. Selection for screening for familial aortic aneurysms. Br J Surg. 1992; 79:897-898. [PubMed: 1422749]

41. Bengtsson H, Sonesson B, Lanne T, et al. Prevalence of abdominal aortic aneurysm in the offspring of patients dying from aneurysm rupture. Br J Surg. 1992; 79:1142-1143. [PubMed: 1308671]

42. van der Lugt A, Kranendonk SE, Baars AM. Screening for familial occurrence of abdominal aortic aneurysm. Ned Tijdschr Geneeskd. 1992; 136:1910-1913. [PubMed: 1407165]

43. Adams DC, Tulloh BR, Galloway SW, Shaw E, Tulloh AJ, Poskitt KR. Familial abdominal aortic aneurysm: prevalence and implications for screening. Eur J Vasc Surg. 1993; 7:709-712. [PubMed: 8270076]

44. Moher D, Cole CW, Hill GB. Definition and management of abdominal aortic aneurysms: results from a Canadian survey. Can J Surg. 1994; 37:29-32. [PubMed: 8306216]

45. Fitzgerald $\mathrm{P}$, Ramsbottom D, Burke $\mathrm{P}$, et al. Abdominal aortic aneurysm in the Irish population: a familial screening study. Br J Surg. 1995; 82:483-486. [PubMed: 7613891]

46. Larcos G, Gruenewald SM, Fletcher JP. Ultrasound screening of families with abdominal aortic aneurysm. Australas Radiol. 1995; 39:254-256. [PubMed: 7487760]

47. Jaakkola P, Kuivaniemi H, Partanen K, Tromp G, Liljestrom B, Ryynanen M. Familial abdominal aortic aneurysms: screening of 71 families. Eur J Surg. 1996; 162:611-617. [PubMed: 8891618]

48. van der Graaf Y, Akkersdijk GJ, Hak E, Godaert GL, Eikelboom BC. Results of aortic screening in the brothers of patients who had elective aortic aneurysm repair. Br J Surg. 1998; 85:778-780.

[PubMed: 9667706] 
49. Salo JA, Soisalon-Soininen S, Bondestam S, Mattila PS. Familial occurrence of abdominal aortic aneurysm. Ann Intern Med. 1999; 130:637-642. [PubMed: 10215559]

50. Frydman G, Walker PJ, Summers K, et al. The value of screening in siblings of patients with abdominal aortic aneurysm. Eur J Vasc Endovasc Surg. 2003; 26:396-400. [PubMed: 14512002]

51. Ogata T, MacKean GL, Cole CW, et al. The lifetime prevalence of abdominal aortic aneurysms among siblings of aneurysm patients is eightfold higher than among siblings of spouses: an analysis of 187 aneurysm families in Nova Scotia, Canada. J Vasc Surg. 2005; 42:891-897. [PubMed: 16275443]

52. Badger SA, O'Donnell ME, Boyd CS, et al. The low prevalence of abdominal aortic aneurysm in relatives in Northern Ireland. Eur J Vasc Endovasc Surg. 2007; 34:163-168. [PubMed: 17470405]

53. Linne A, Lindstrom D, Hultgren R. High prevalence of abdominal aortic aneurysms in brothers and sisters of patients despite a low prevalence in the population. J Vasc Surg. 2012; 56:305-310. [PubMed: 22425245] 


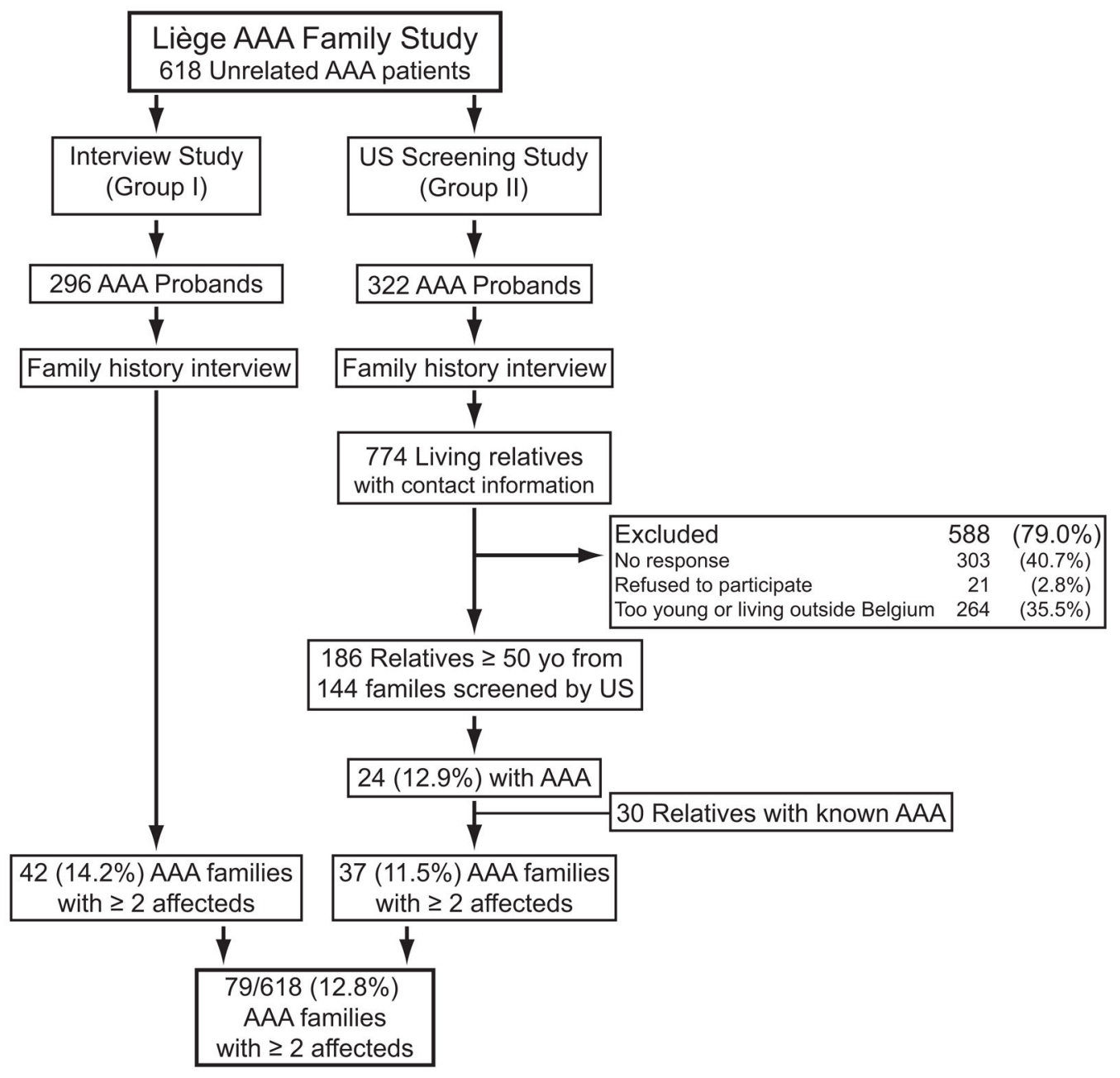

Figure 1.

Outline of the Liège AAA Family Study with 618 Probands. The objectives of the study were to determine 1) what percentage of AAA patients (referred here as "AAA probands") have a positive family history for AAA, 2) what is the prevalence of AAAs among relatives of AAA probands, and 3) whether familial AAA (FAAA) cases differ from non-familial (sporadic) AAA cases in clinical characteristics, using a well-characterized population in Liège, Belgium. US, ultrasonography; AAA, abdominal aortic aneurysm. The number of individuals in each group and the proportion $(\%)$ are indicated. For the US screening, relatives $\geq 50$ years of age were invited to participate and the numbers shown represent this age category. 


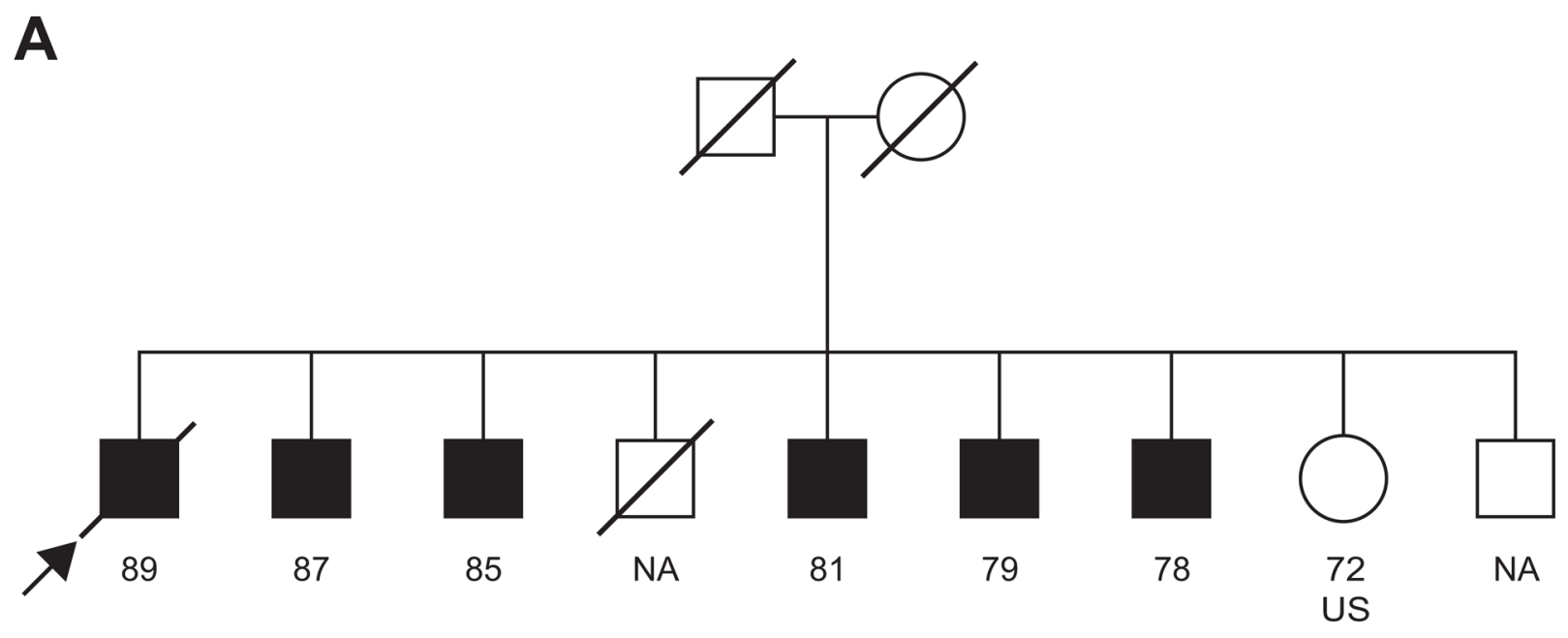

B

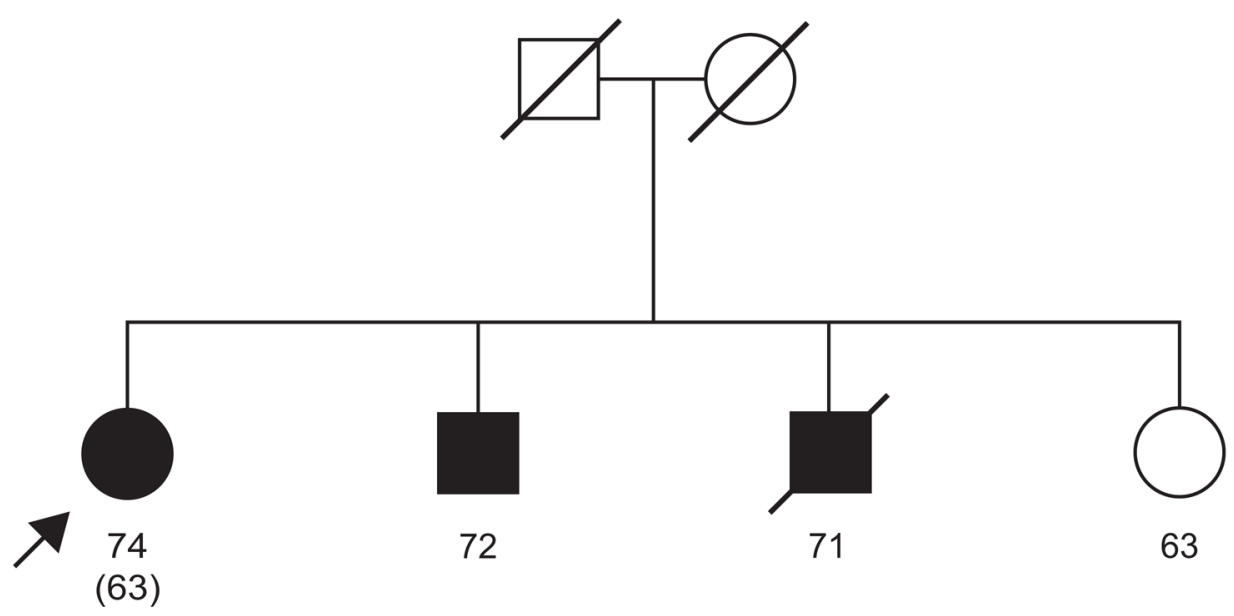

Figure 2.

Two AAA families from the Liège AAA Family Study. The proband in each family is indicated with an arrow. Slash across symbol means death. Black squares and circles, males and females, respectively, with AAA. NA, the person did not participate in US screening. US, the person had ultrasonography examination which showed no AAA. The number below each symbol indicates the age of the person at the time of recruitment, which for most individuals was also the age at the time of AAA diagnosis. If these two ages differed, the age at diagnosis is shown in parenthesis. 


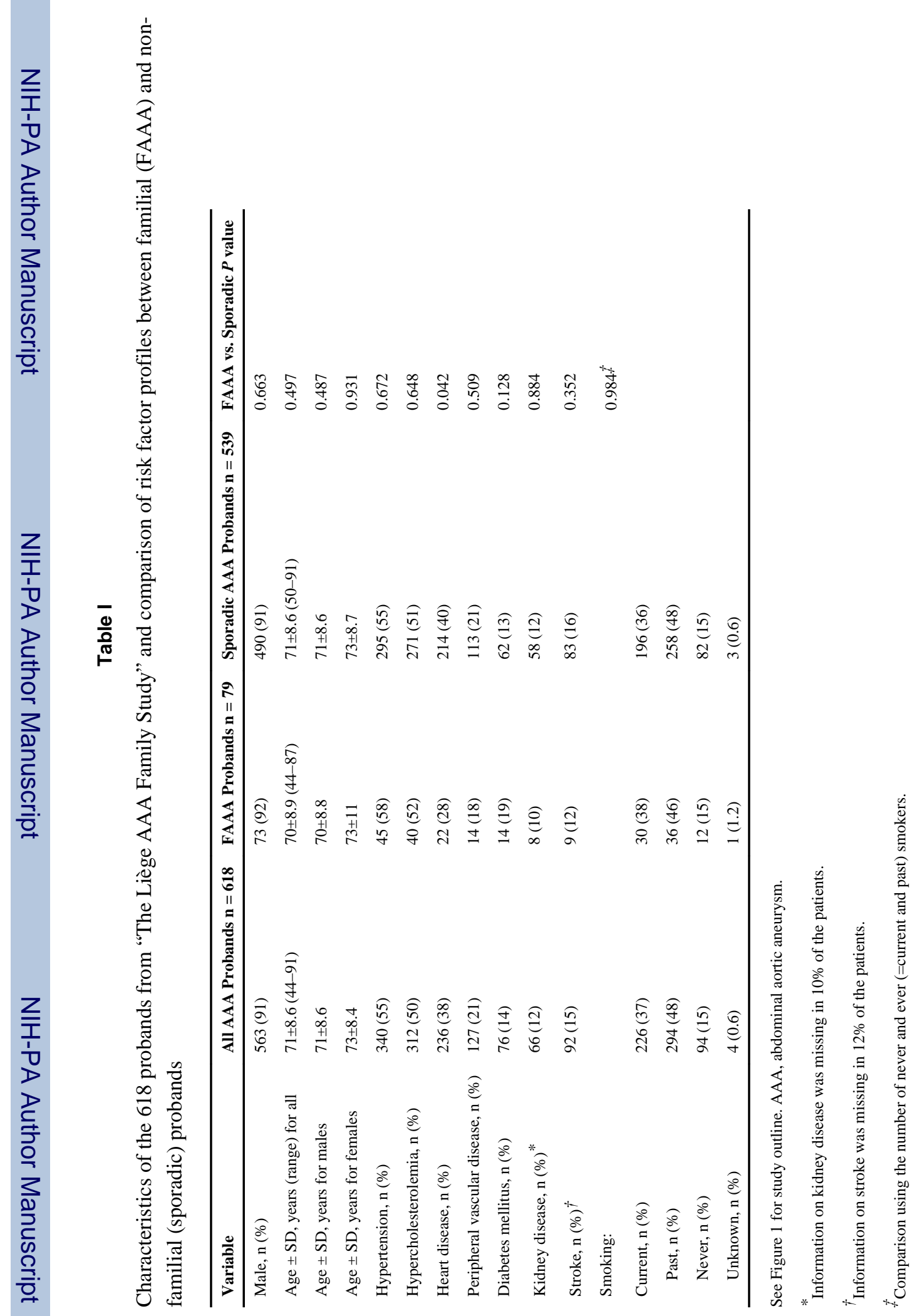




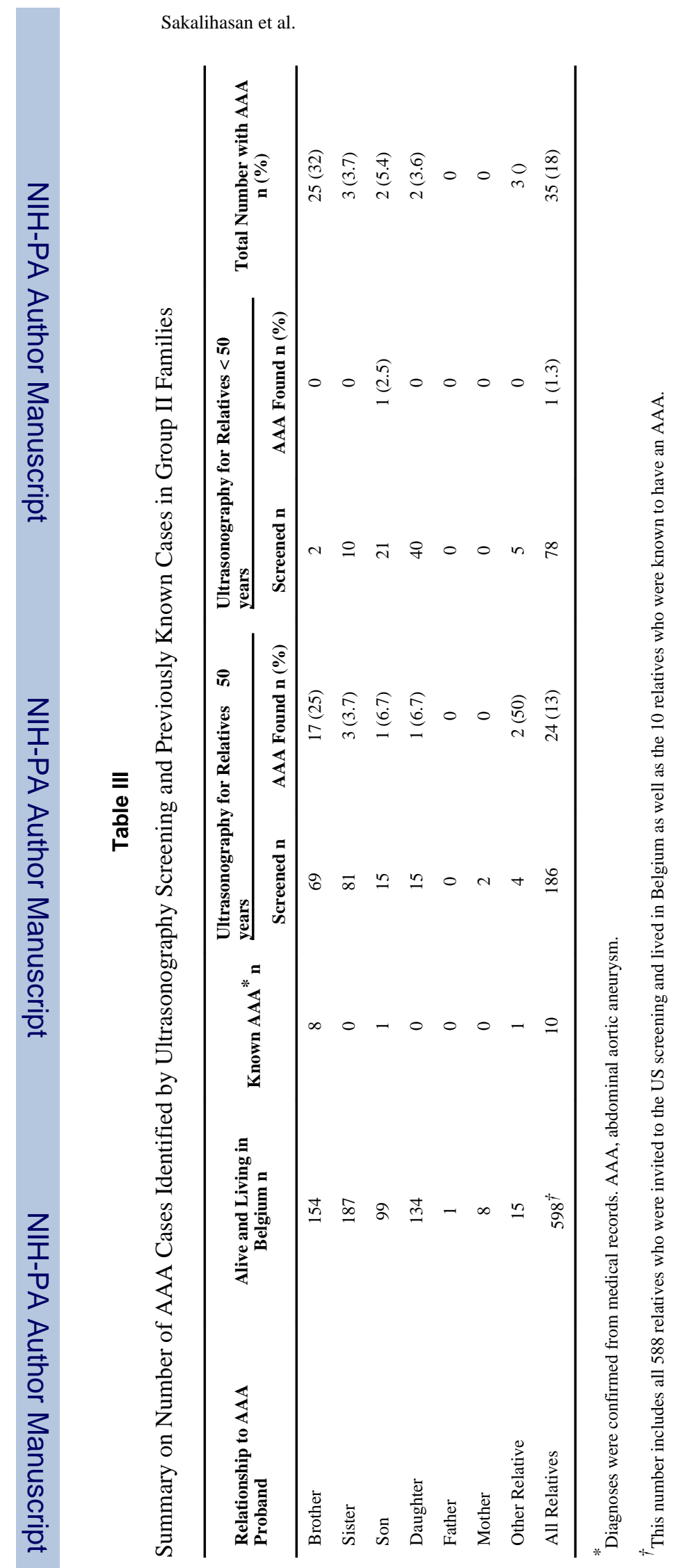

Ann Vasc Surg. Author manuscript; available in PMC 2015 May 01. 


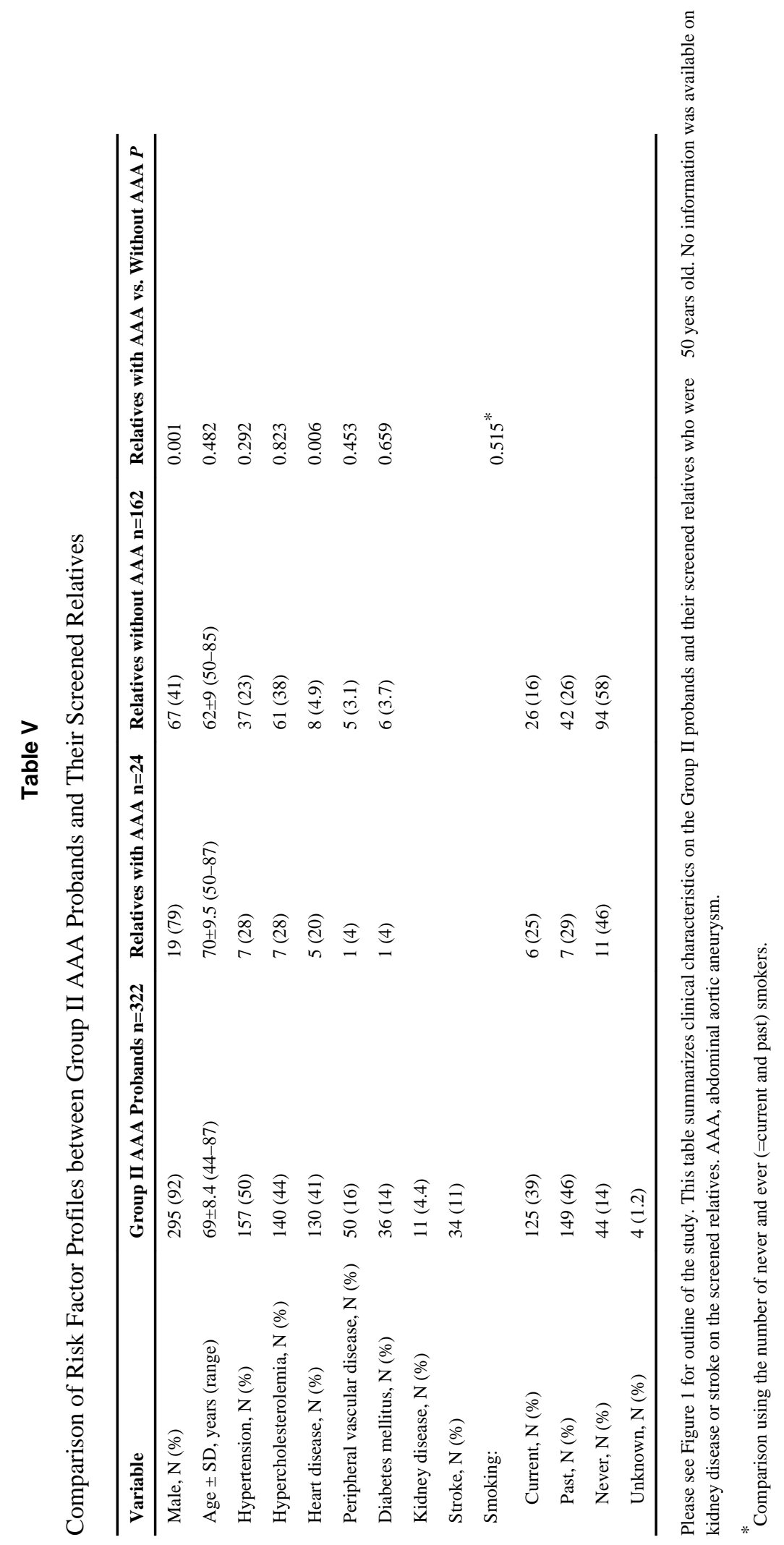

Ann Vasc Surg. Author manuscript; available in PMC 2015 May 01. 


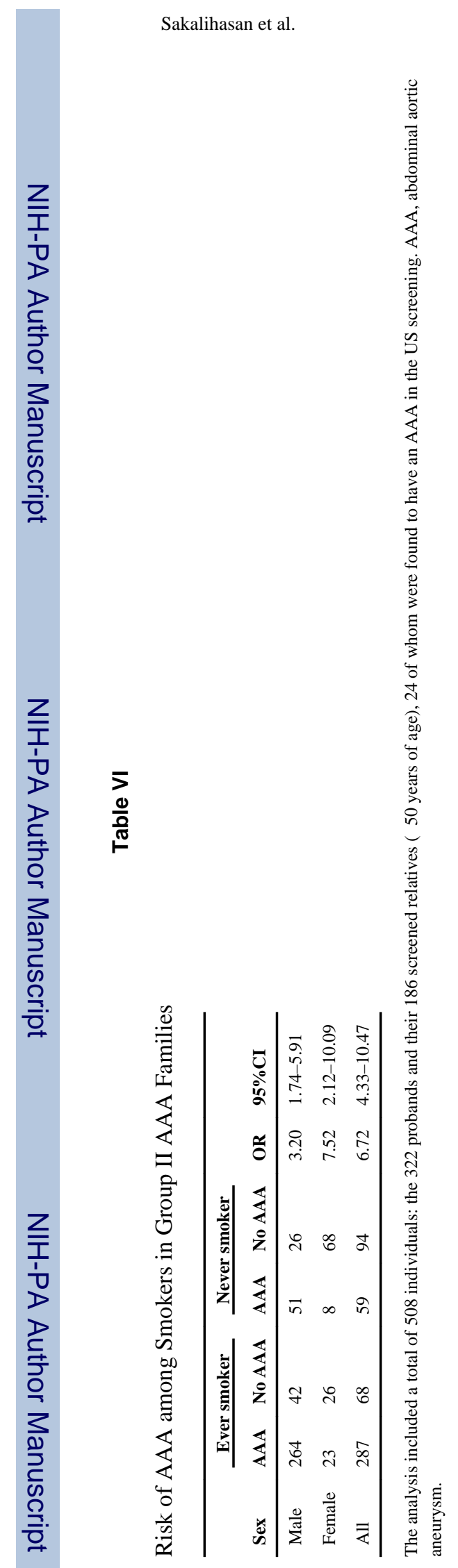

Ann Vasc Surg. Author manuscript; available in PMC 2015 May 01. 


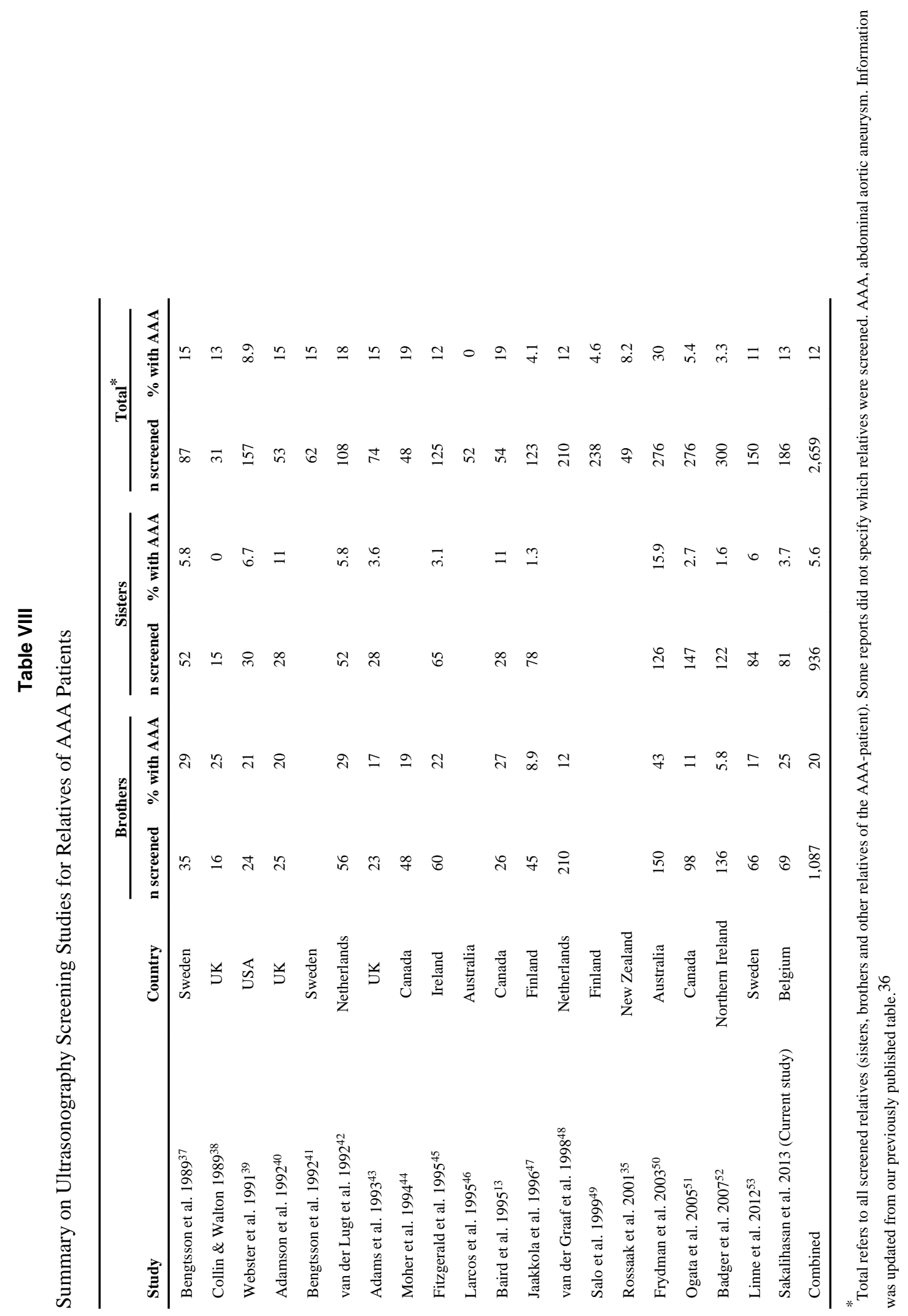

